\title{
Monolingual \& Bilingual Dictionaries as Effective Tools of the Management of English Language Education
}

\author{
Al-Nauman Al-Amin Ali El-Sayed \\ English Department, College of Science \& Humanities, Dawadami, Shaqra University, KSA 11911 \\ Ahmed Gumaa Siddiek (Corresponding Author) \\ English Department, College of Science \& Humanities, Dawadami, P.O.Box 18, Shaqra University, KSA 11911
}

\begin{abstract}
Language teaching is a complex job, where technical and professional skills are highly needed to master the use of modern teaching aids that facilitate effective presentation inside the classroom. A dictionary be - monolingual, bilingual or bilingualised- is an effective teaching tool, but it is often neglected, while it should always be consulted and included in every EFL syllabus or in any EFL teaching/learning situation. It should constantly be referred to by teachers to enhance their teaching strategies and learners should resort to it to develop linguistic skills. Thus a dictionary can be seen as a tool that can help in the management of language education. It can be effectively used to create a comprehensive pedagogical environment; not only targeting the look-up for the meaning of words, but also featuring other important aspects of language skills which a good dictionary can-simultaneously- provide to teachers and learners as well.
\end{abstract}

Index Terms - lexicography, monolingual, bilingualised dictionaries, pedagogical environment. Language management

\section{OVERVIEW}

Since their beginning in the 18th century, English dictionaries have been viewed as the ultimate authority on English language as in The Dictionary by Dr. Johnson (1747), The Webster Dictionary (1855) and Oxford English Dictionary (1933). This has been to such a degree that a dictionary is referred to as an equal stance with the Book (i.e. the Bible), thus suggesting an aura of reverence. The indication of sacredness has changed little with the appearance of pedagogical monolingual English dictionaries geared to the English language learner. From the modest beginning of these dictionaries in the slim volumes by West (1935) and Hornby (1948) and up to the latest corpus-based dictionaries, as Collins-COBUILD Dictionary in the 1990s, dictionaries have found their place and been included as an essential part of language leaner's indispensable equipment. They are regarded by many as the repository of final linguistic authority (Wright, 2001) and a bank account of words to be drawn upon in time of need.

Today, English pedagogical lexicography has changed considerably. It is now a flourishing field that has gathered momentum in the last three decades for three reasons. First, there has been a renewed interest in the nature of the lexicon and vocabulary acquisition, features invariably linked to dictionaries (e.g. Lewis, 1993; 1997; Nation, 2001; Koya, 2005; Nesselhauf, 2003; Sessink, 2007). Second, simultaneously with the interest in vocabulary, there has been a huge advance in compilation and analysis of written and spoken corpora through the tools of computational linguistics which has eased the tools of traditional lexicographers and enabled them to produce dictionaries based on new insights (Sinclair, 1995). The result was an explosion in dictionary-making publishing industry, mainly of the British type. Thirdly, as has been convincingly demonstrated by Crystal (1997) and Graddol (2000), English has become a truly international language, and that in our interdependent, shrinking, global village there is no escaping English as being the lingua-franca of written and oral communication. Therefore, everyone with ambition is trying to learn English and, naturally, EFL dictionaries come in the picture, because they provide the most explicit description of the meaning and use of words of this language, a tool essential to the language process.

Indeed, a dictionary is the first thing an EFL student buys (Baxter, 1980) and learners carry dictionaries around, not grammar books as someone said. Hence, EFL students have a powerful tool at their disposal with which to gain further understanding of a range of a new language, leading eventually to accurate production and comprehension. Then, a dictionary serves as a means whose purpose is to provide information about language which can be applied to a variety of activities. A successful dictionary can show students the possibilities of language and is capable of providing a wealth of information. However, being able to use a dictionary is obviously not an end in itself; we use it, according to Stein (2002-11), to understand what someone has said, or what we are reading, or to be able to express what we want to say. In short, a dictionary is an aid to understanding.

That the dictionary is an essential learning tool is being increasingly acknowledged (Hartmann, 1999). However, other researchers such as Garcia (2005), notes that the spate of dictionary production has not been matched by an 
adequate research into the type of users and language skills needed for the exploitation of dictionaries. In fact, Atkins (1998) points out that, out of the four EFL dictionary research areas, namely history, typology, criticism and users, the last has only begun to be addressed. Rundel (1996), adds that this has only come about as an off-shoot of the rise of learner-centred view of learning. The focus on users will reveal much about users and their dictionaries. This is essential if language learners are to reach their full potential, and if EFL monolingual dictionaries (which is the focus of this thesis) are to be tapped for the maximum benefit. However, this paper will shed light on the importance of dictionaries as authentic source of knowledge and effective tools of language education. A separate research on dictionary users will be tackled in another article, as this survey is interned to only cover some historical development of monolingual and bilingual dictionaries and their importance as language vital teaching devices.

\section{Rationale}

While monolingual English dictionaries have been the focus of a considerable body of research (e.g. Atkins, 1985; Bejoint, 1994; Stein, 1991, 1999, 2002; Hartmann, 1989, 1991, 2005, and Wright, 2001), limited efforts are exerted to remind with the impotence of the dictionary as a teaching tool. A sufficient interest and awareness should have been developed among language teachers and syllabus designers about the importance of this teaching aid. Dictionaries, however, do not only instruct and enlighten the students (Scholfield, 2001), despite the wealth of information they contain in terms of phonology, morphology, grammar and semantics, and so students think of them as just another book to help them look up words, while the under use of dictionary might be attributable to lack of instruction in the area of lexicography, its omission from the syllabus, and lack of conviction on the part of (old-fashioned) teachers to teach the myriad aspects of dictionaries. The consequences are observable - that student's oral and written production is often characterized by inappropriate word and phonological choice, lack of grammatical, lexical and semantic precision and social constraints on discourse. Hence, this survey will try to shed light on the historical features of monolingual and bilingual dictionaries in the field of language teaching, as a part of teachers' job to realize their impotence and use them as a part of routine work in their classrooms.

\section{INTRODUCTION}

This section will investigate the different theoretical and practical aspects of EFL monolingual dictionaries to introduce the theme of the study. First, it defines such dictionaries by contrasting them with other types. Then, relates EFL lexicography to pedagogical practices in classroom teaching, learning and syllabus design.

\section{A. What Is a Dictionary?}

In its etymology, the modem term 'dictionary' comes to us from Latin "dictionarium" through French "dictionaries" which properly means "a book of sayings" (Hartmann, 1992, p. 5). However, in its modem usage, the word "dictionary" has become synonymous with that book containing lists of words with information about them. This belief is held by (Crystal (1987:108) who conceives of a dictionary as a reference book that lists words in alphabetical order. Crystal (ibid) also differentiates between the two senses of the word "dictionary": a reference book in a living room or on a library shelf, and an inbuilt dictionary which every native speaker of a language carries with him as part of his mental equipment.

A comprehensive definition of the dictionary is suggested by Zgusta (1971: 197) in his authoritative text on lexicography:

"A dictionary is a systematically arranged list of socialized linguistic forms compiled from the speech habits of a given speech community and commented upon in such a way that the qualified reader understands the meaning of each separate form, and is informed of the relevant facts concerning the function of that form in its community ".

\section{B. Types of Native English Monolingual Dictionaries}

Monolingual English dictionaries began as a listing of "hard words", i.e. wordlists that explained in plain English the poorly Anglicized Greek and Latin vocabulary. Yet, gradually common words were also included and a goal was set to provide a comprehensive coverage of the English language. Early examples of these efforts were Dr. Johnson's (1747) "The Dictionary" and Webster's (1851) "The Dictionary of the American English". Gradually, a lexicographical tradition had built up made of the variety of native speakers' monolingual dictionaries to the extent that it is this general - purpose type of dictionary that most native speakers buy and conceive of as the dictionary, and it is this type of a dictionary in all its manifestations is the focus of this study. This sort of dictionary contains an alphabetical listing and includes a substantial body of the English vocabulary within the limits of their size. At the top of this type comes the Oxford English Dictionary (OED) composed over a period of fifty years (1880-1930) and including 20 volumes that trace the history and development of English words (Stein, 2002). Other kinds of monolingual native dictionaries have evolved and can be grouped according to Jackson (1988: 160) into four types. First, there are the very large library dictionaries like Webster's Third International Dictionary covering over 400,000 English words. Second, there are the desk dictionaries like Collins English Dictionary (about 1650 pages with 170,000 words) and the Longman Dictionary of English Language and Chambers' Twentieth Century Dictionary. Third, there are the "concise" dictionaries (about 1300 pages with 162,000 words) such as Oxford Concise Dictionary of Current English, the New Collins Concise 
English Dictionary and the Longman Concise Dictionary. Finally, there is the "pocket" or "compact" dictionary (about 900 pages with 70,000 words) like Oxford Pocket English Dictionary and the Collins Pocket English Dictionary.

In addition to the above general reference works, more specialized dictionaries concerned with particular aspects of English have been compiled to meet the needs of native speakers. These areas include dialects, slangs, and historical, literary, technical, etc. varieties of English. Among the prominent examples of specialist dictionaries cited by Jackson (ibid) is Cassel's Spelling Dictionary. It lists root words alphabetically and under each root the inflectional and derived forms, on the grounds that most spelling problems are at the morpheme boundaries between root words and inflections. There is also Daniel John's famous "Everyman's English Pronunciation Dictionary" which contains roughly 60,000 words with their pronunciation given in International Phonetic Alphabet (IP A). The researcher can think of more recent examples such as Cowie's "The Cambridge Dictionary of Idioms" which is a comprehensive account of all types of English idioms that highlights an area that has become increasingly important in the last two decades.

\section{Native vs. Non-native Speakers' Monolingual English Dictionaries}

In the previous section a mention was made of the dictionaries specifically designed for the native speakers. However, with the spread of English as the lingua-franca since the beginning of the 20th century the above dictionaries have been modified to "meet the needs of millions of English speakers around the world. Though the prominent examples of EFL dictionaries are mainly for the advanced students (such as Oxford Advanced Learner's Dictionary (OALD), the Longman Dictionary of Contemporary English (LDOCE), Chambers Universal Dictionary (CULD) and (COBUILD) Contemporary English Dictionary (CEDELD), smaller dictionaries have been made for lower proficiency levels, by the three above leading EFL publishers. The premise of EFL lexicography is the fact that foreign language learners especially the advanced ones who are our interest in this thesis consult dictionaries for reasons different from those of the native speakers, and thus EFL dictionaries contain a specific type of information not found in the former. Cowie (1993) accurately pinpoints the expectations of the two types:

1- The EFL student is interested more in the treatment of common words. The $\mathrm{L}_{1}$ student looks, however, for rare words with no compounds.

2- The EFL dictionary wordlist has a balance of neologisms and technicalities, whereas a general dictionary has various technicalities, neologisms, etc.

3- Native-speaker dictionaries are for decoding activities e.g. reading and spelling, whereas EFL dictionaries are more interested in encoding (e.g. writing) activities.

4- Since EFL students are still learning the language, the defining vocabulary of EFL dictionaries is kept relatively simple unlike the full-fledged definitions of native dictionaries.

5- EFL and native dictionaries may differ regarding pronunciation. In the latter, pronunciation is indicated either by a respelling or by symbols of the international phonetic system. EFL dictionaries use the latter only.

6- In order to help the EFL learners to strike the right stylistic level, EFL dictionaries contain more explicit reference to language use. This is done by means of usage labels and notes.

7- As a further help to learners, EFL dictionaries provide a considerable number of example phrases and sentences which show the item under consideration in actual use.

To put these differences in concrete forms, let us cite Jackson (1988: 176) who compares entries for the item of "inform" in a native English dictionary, the Longman Concise English Dictionary and an EFL dictionary, the Longman Dictionary of Contemporary English (CLDOCE). The learner's dictionary, unlike the native's, does not include etymology for the word because it is perceived to be of no relevance to the learner of the language. Also, the first sense of inform in LCED is not mentioned in LDOCE because it is the older sense of inform and is rare and so the learner is not expected to need it. The striking features of LDOCE entry is the wealth of information it pays to how the word is used in the language: there is detailed syntactic information given in codes ' $T$ ' of ' $C$ ' of, about, (obj) + (that) etc. and there is an example to illustrate each of the syntactic constructions and the meaning. Finally, the exemplification of the headword given and levels of usage included in LDOCE are lacking in LCED.

\section{Bilingual Dictionaries}

In Bilinguals, the student can use his/her language to understand the target language. The information in the source is provided through translational equivalents Atkins (1985), mentions other features like the formal or informal equivalents, etymology, synonyms, and pronunciation. An example can be seen on Al Ba'labaki English - Arabic Dictionary (2003).

\section{E. Monolingual and Bilingual Dictionaries: A Comparison}

One of the central issues in EFL lexicography is deciding which dictionary is better. Despite all that, it would be useful to review the arguments in favour and against both types. There is a fairly clear difference in the attitudes of students on one hand who prefer bilingual dictionaries (Baxter, 1980; Benoussin and Atkins, 1990), and teachers who encourage the use of monolingual dictionaries on the other (Yorkey, 1992; Stein, 2002). Bilinguals are better in that there are often $\mathrm{n}$ equivalents in the source language like in flora and fauna words (Landau, 1989), for many words are culture-bound like the social terms and plants. For example, Stein (2002) provides two examples of definitions, one for a plant and one for an animal. 
If we now try to derive the headword from the explanation we will find they are inadequate to identify the headwords with certainty (in the above cases "carnation" and "mouse") but a bilingual will provide the exact equivalent in the student's native language. While writing an essay or letter in which case the monolingual offers little help as learners can access the material in the dictionary only by means of a foreign language headword. It might be just that word that they do not know, and if that is the reason for the difficulty, the situation becomes circular with no way out.

However, this ease of access which is the hallmark of bilinguals has its negative side. Bilinguals only provide translations; the students constantly switch from the mother tongue to the foreign language, thus furthering their beliefs that languages are simply nomenclatures and hiding meaning discriminations. Moreover, bilinguals create a translation barrier by concentrating on isolated words and internalizing $\mathrm{L}_{2}$ items against the social and cultural $\mathrm{L}_{1}$ items thus veiling the anamorphic nature of language (Zgusta, 1971).

If ease of access is the chief attraction of bilinguals, it is one of the main difficulties in using monolingual dictionaries. Hartmann (1992: 153), mentions that students less proficient in L2 may not be able to benefit much from them. However, the rewards are correspondingly great: a monolingual with its reliance on target language and capacity for paraphrases of many meanings deliberately provides a wealth of semantic, grammatical and stylistic wealth of information that encourages production language activities. Also, Underhill (1984) believes that monolinguals help students think in the target language and get out of the translation rut, so promoting their confidence in dealing with another language and hence are led to formulate questions and look for answers on their own. Hartmann (1992) goes a step further and claims that the very fact of using a monolingual dictionary is a useful search experience that might yield more learning fruit than the student had originally intended.

We can draw a number of conclusions from the above discussion. First, the dichotomy in teachers' and students' preferences for one type or another is clearly irreconcilable. Also, to argue for strictly one type is a major misjudgment as both have their good sides, though it would seem that the natural progression is from a bilingual to a monolingual which is unquestionably more rich in information, but it is becoming increasingly clear that each kind helps students in performing certain activities at different stages in distinct ways and are not mutually exclusive. Hartmann (2002) emphasizes this point precisely by stating that the idea of "weaning away" students from bilingual dictionaries is unsound, and that by focusing on how the languages contrast semantically, syntactically, pragmatically and culturally, bilinguals may assist learners in ways that monolinguals cannot. One way out of the dilemma has been the suggestion of researchers like Atkins (1985) of writing dictionaries that combine the best features of monolingual and bilingual dictionaries, which is the topic of our next section.

\section{F. Bilingualised Dictionaries}

From the previous section it is clear that neither the monolingual nor the bilingual dictionary is perfect in itself, and in many ways the good side of both is complementary. This fact led researchers such as Atkins (1985:22), to forward the view that the rigid dichotomy between monolingual and bilingual dictionaries should be overcome by using a hybrid type incorporating features of both: the bilingualised dictionary. The bilingualised dictionary has grown in popularity for the simple reason that it is a compromise between the monolingual and bilingual dictionary. It is a result of an adaptation of the unilingual English learner's dictionary which has all or part of its entries translated into the mother tongue (Hartmann, 1992:243). He (ibid) remarks that the bilingual dictionary falls in line with the double criticism on that, on one hand, monolingual learners' dictionaries are still too much like native speakers' dictionaries, and, on the other, straightforward bilingual dictionaries are too far removed from the target language to be of great use. Other writers like Stein (2002:17) substantiates the grounds for bilingualised dictionaries from our daily experiences: we use both types of dictionaries as teachers when we read an English newspaper or a novel as we look up unknown items in a bilingual or monolingual dictionary, and when we are writing a letter or an essay in English, we double-check the spelling equivalents offered by our bilingual dictionaries in the monolingual EFL dictionary.

The bilingualised dictionary is the supposedly happy marriage of the above-mentioned paradigms. It contains the $\mathrm{L}_{2}$ definitions and examples of the monolingual dictionary and accessible $\mathrm{L}_{1}$ equivalents of the bilingual dictionary. This dictionary is often based on existing EFL monolingual dictionaries. The earliest example dates back to 1966 for Chinese learners and was an adaptation of OALD (Hartmann, 1992:154). Other examples included: "The Oxford Students' Dictionary for Hebrew Speakers" (1990). Here definitions in English are followed by a Hebrew gloss in stylistically similar language. "The Oxford Intermediate Learner's English-Chinese Dictionary" (1988), and "The Oxford English Greek Learner's Dictionary" (1989). The researcher can add more examples to the list from his study of a particular bilingualised dictionary available in local markets known with "The Oxford Word power English-Arabic-English Dictionary". It is a dictionary that gives translations into Arabic of the English entries (the key or main parts, according to Reif (1987). Unlike the purely bilingual dictionary, however, it gives very little translation of the meaning of each word, mostly one or two Arabic words per entry. The greater amount of information given in English, on the other hand, further helps the reader pinpoint the precise meaning and usage of the word once the translation has been understood. Thus, deep understanding is attained through the English part i.e. the definition, and the examples, whereas a quick and general understanding is obtained through the Arabic part. This will become evident in the Oxford English-ArabicEnglish Bilingualised Dictionary

But while acknowledging their advantages, critics have found difficulties with bilingualised dictionaries: additional space is required in entries in some works, and thus other material may have to be sacrificed. Some scholars complain 
that the translation may be tempting to students who may only study the entry and its translation, but nothing else and thus obtaining even less information than that attained by the user of a strictly bilingual dictionary. A related drawback was pointed out as to do with the problematic notion of "key" word or translation; as it is simultaneously designed to be a competent translation of the headword but draws as little attention as possible to itself. The above argument may be emphasized that the readers may skip definitions and examples altogether and instead only pick up the translation offered. Our own reservation about bilingualised dictionaries is their unsuitability for EFL students of English who we believe should have their knowledge of English reinforced through use of English that is the use of EFL monolingual dictionary. However, this point should not eclipse the fact that bilingualised dictionaries have come to stay, and that they offer undeniable benefits especially for elementary and pre-intermediate students of English.

\section{G. Electronic Dictionaries}

Electronic dictionaries are a relatively new development as far as EFL dictionaries are concerned, but one which has already posed a threat to the more traditional types. Electronic dictionaries are seen as converted paper dictionaries, not the other way round, as all electronic dictionaries have the common feature that the data is stored on electronic computer files, and that a computer is needed to use these dictionaries. These dictionaries come in various formats such as hand-held monolingual pedagogical dictionaries - the dictionary is stored in a piece of hardware dedicated only to some specific tasks such as dictionary browsing, (e.g. Handheld Longman. Dictionary of Contemporary English (Docherty, 2000). Better known are dictionaries to be used in computers (either hand-alone or networked) similar as the other applications. The standard medium is now CD-ROM, or one of its modifications such as DVD dictionary. Dictionary files are typically kept on CDs; only the application and some indexes are written to the hard disk of the computer. Sharpe (2003) notes also the recent accessibility of traditional dictionaries via the internet.

Authors such as Chans (2004), view the CD-ROM format positively as the most convenient form. A CD can hold an enormous amount of information, and it can store not only the text of the dictionary but also multi-media such as pictures, sound or video. CDs are also fairly cheap to produce and do not take up much shelf room. An electronic dictionary clearly surpasses the printed original in the possibility of use potential. Also the electronic dictionary enjoys the capabilities of multi-media contents, i.e. the addition of sound and pictures, often moving videos to the body of the dictionary. Thus, traditional pictures are enhanced by the use of several sensory channels such as sound and slide, images and graphics from real life to illustrate a word or an expression.

On the other hand, there are clearly some disadvantages mentioned by Nesi (2001) in that the user views only the entry (and its translation) in addition to the part of speech label, but usually nothing else. This construction narrows down the learning process since the only thing one can learn in such a situation is that there are one or two equivalents or definitions given for the entry, unlike the printed dictionary where there is a whole page with other words from the same family as well as idioms and common phrases related to the same entry. Also, most electronic dictionaries give students much less information than printed dictionaries do. Very few of the current electronic dictionaries give more than merely spelling, part of speech, and one or two translations. For Zahner (1999) another criticism of the electronic dictionary is that it does not fully exploit the computer ability to process and display lexical information in a flexible way. It cannot be modified and offers only limited facilities, usually translations.

However, the current attitudes to the electronic dictionary may change with the invention of better ones that will offer the user far greater advantages than printed dictionaries. One idea for such an electronic dictionary is suggested by Zahner (2004). Comparing the mental and computer lexicon, the author suggests an electronic dictionary which will be able to provide a much more user-friendly interface with all huge megabytes of information spelled out and additional help information on the metalanguage provided where necessary. The user will be able to browse through different functions and explore a word's relationships with other words, its occurrence in set expressions of common idioms, and its place in multi-dimensional semantic network. The author suggests incorporating this dictionary in computer-assisted language learning (CALL) programmes to enable the user add more items at his or her own choice.

The electronic dictionary requires skills or habits different from those required by a printed dictionary. The requirements for the former resemble "computer skills" which do not take long to master. Among them is the habit of seeing information pop up after clicking some buttons without really having to scan, contrary to the "dictionary skills" which demand a lot of skimming and scanning as well as reading, especially in the monolingual, bilingual, and bilingualised dictionaries. Zahner (2004: 18) believes that technological progress is inexorable, and that in our world where convenience are rules at the expense of quality, it seems likely that printed dictionaries will be obsolete, and that their electronic counterparts will do their job more efficiently. As Sharpe (2000) puts it, the advantages of the electronic dictionary and the familiarity of today's young people with electronic devices, will eventually relegate the printed notion of "dictionary" to a secondary sense. However, until such time arrives, we will focus, as in the present research, on the more widely used traditional EFL dictionary.

\section{H. Components of EFL Monolingual Dictionaries}

Entries differ in content and organization from one EFL dictionary to another. Yet, certain standard components have been identified by Atkins (1985) as follows:

1. Lexemes.

2. Spelling. 
3. Indication of pronunciation.

4. Grammatical information (including parts of speech, morphological information and verb patterns).

5. Definition.

6. Illustrative examples.

7. Idioms.

8. Graphic illustrations.

9. Cross-reference.

10. Etymology.

11. Stylistic variations.

Some of the above features have been illustrated in the following diagram from Stein (2002:21) as follows:

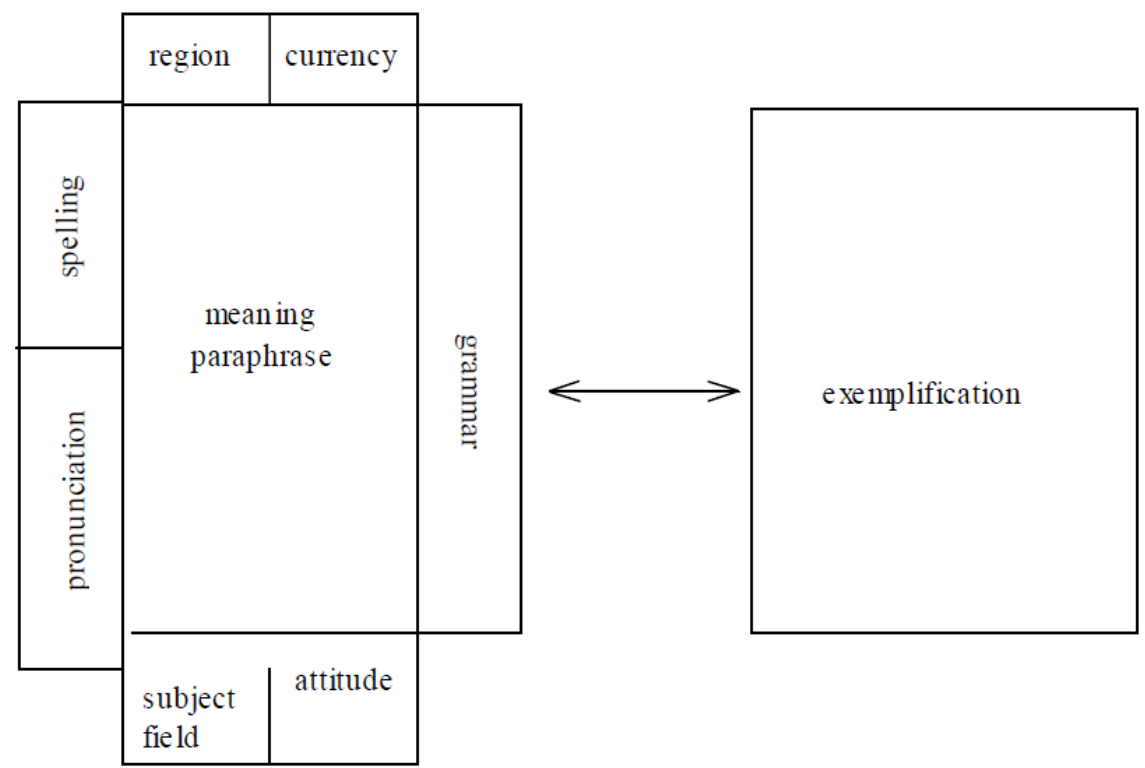

Fig. 2.4 Features of the EFL dictionary entry components

The above eleven components need to be considered in some details in a separate research, as they are the backbone of any entry in an EFL monolingual dictionary. Theoretical discussion of these components can be reinforced by constant reference to the four established British EFL monolingual dictionaries: OALD, LDOCE, CULD and CCELD.

\section{A Model of Learners' Decoding and Encoding Dictionary Use Strategies}

The increasing interest in recent years in EFL dictionary use has led researchers to investigate and conceptualize how students employ dictionaries for the two functions of decoding and encoding. The most well-known of these models is the one by Schofield (1982) which is concerned with the strategies users must follow while employing dictionary for decoding purposes. Schofield (1982: 186) suggests that the practice of looking-up and understanding information needed for comprehension can be broken down into seven steps:

1- Locate words and phrases you do not understand.

2- If the unknown form is inflected, remove the inflection to recover the form to look up (the canonical form).

3- Search for the unknown form in alphabetical list.

4- If you cannot find out at least one main entry for the unknown, try the following procedures:

5- If the unknown seems to be a set phrase, idiom or compound word, try looking up each main element.

6- If the unknown seems to have a suffix, try the entry for the stem.

7- If the unknown appears to be an irregular inflected form or a spelling variant, scan nearby entries:

8 - If there is an addendum, search there.

9- If there are multiple senses, or homographic entries, reduce them by elimination.

10- Understand the definition and integrate it into the context where the unknown was encountered.

11- If none of the senses entered seems to fit, attempt to infer one that does from the senses you have. If more than one fits, seek further contextual clues in the source text to disambiguate.

For Schofield, teaching students these steps requires enthusiasm and energy, yet they need to be mastered so that users can find their way around a dictionary. Steps 1-4 deal with the macro-structure. With step (1), certain language learners must be taught the concept of Latin alphabetical order and will need to practise second and third letter ordering. But, an additional problem for Stein (2002) is that the dictionary may list entry words using slightly modified alphabetical systems. Idioms and various two-word formations are also arranged differently, depending on the dictionary. 'If there is doubt concerning where a lexical item is to be listed, users should list both entries if the cross- 
reference appears (ibid). With step (2), figuring out the base or uninflected form of a word may also be difficult for students who are unaware of the meaning, so certain irregular inflectional forms should be given separate entries. A similar problem may also arise with step (4) (ibid). Determining whether the word in question is part of a collocation, a suffix, or an irregular inflectional form is not always easy for language learners. According to Schofield, in certain cases, if students know this information in the first place, they would not need to consult the dictionary. Finally, steps (5), (6) and (7) concern the microstructure and require of dictionary users to consider the context when making various decisions. Students must apply previous knowledge and the information at hand. While steps 1-4 are somewhat straightforward, the latter steps are not as easily taught according to Schofield (1982), because users must infer meaning and consider a variety of possibilities.

Schofield's model (1982) offers a good example for productive dictionary in decoding purposes. An adapted version was used to guide the training of dictionary use in writing which is the most important encoding activity and is the one which is the case in point here. In this case the teacher should prepare a series of target words for dictionary consultation. One option for collecting target words is students' own composition (Schofield 1996). In writing, for example, the teacher underlines lexical errors in the students' written work and the learner corrects them with the use of the dictionary. An alternative source of target words for dictionary search is to use segments of think-aloud protocols. Segments can be selected in such a way that they include different types of lexical problems.

A modified version based on Schofield's work and dealing with dictionary consultation for writing purposes was devised by Garcia (2005).

It includes the following:

1 - Recovering the canonical from the inflected target words.

2- Selecting an appropriate reference work (be it a monolingual or bilingual dictionary)

3- Searching for target words in the alphabetical list. This step can even work in the case of the user experiencing a tip-of -the-pen state, since often the beginning of the word is retrieved (Garcia, 2005: 255).

4- Scanning all of the definitions or translations in the entry for the one closest to the meaning of the writer to be expressed before taking any decision.

5- Reading the examples, grammar code, collocation information and style labels and finding the ones that best fit the context in which the target word is to be used.

6- Cross-referencing, if the word was sought in a bilingual $\left(\mathrm{L}_{1}\right.$ to $\left.\mathrm{L}_{2}\right)$ double-check the translation of the candidates in the $\mathrm{L}_{2}$ to $\mathrm{L}_{1}$ section or in the cases of a monolingual search, use a thesaurus for double-checking the candidate words.

7- Adding any inflections that were eliminated during original search to fit the linguistic context in which they will be used. The following schematic figure by Garcia (2005:251), better illustrates steps normally employed by students when using a dictionary for writing: 


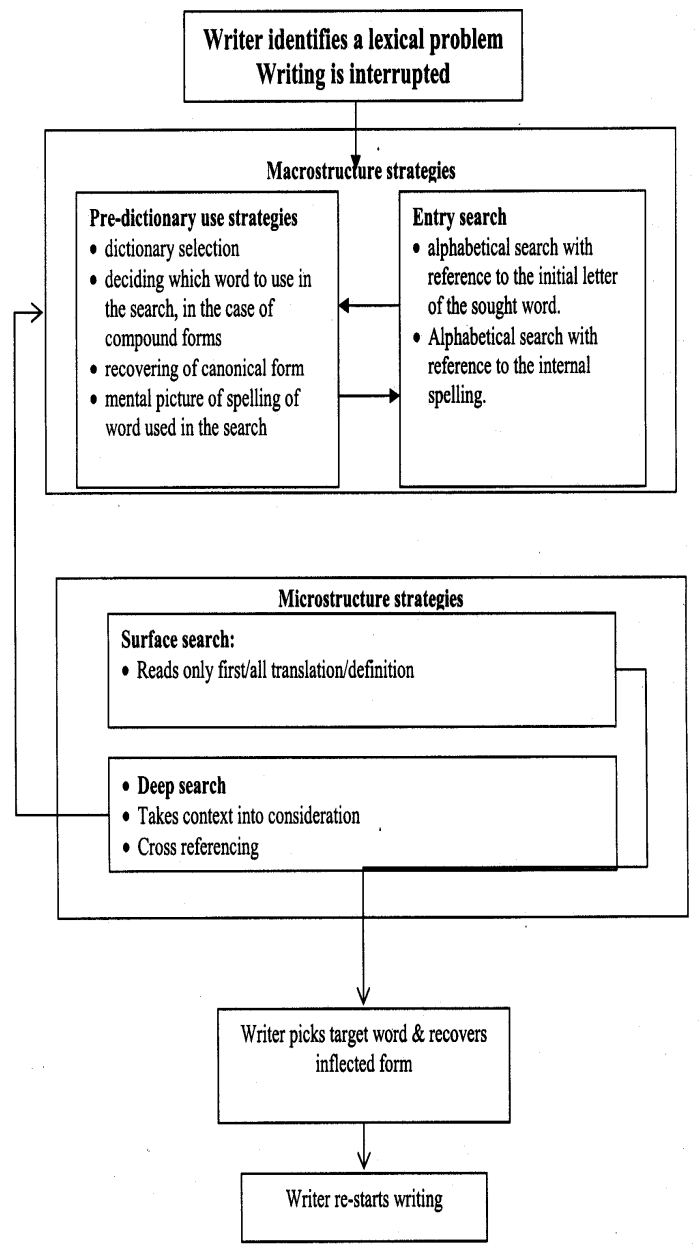

Fig. 2.11 Strategies Employed During Dictionary Search Source: Garcia (2005), University of Essex.

\section{J. Problems in EFL Dictionaries Use}

A foreign language learner, who is confronted with a linguistic difficulty, be it in reception or production, may feel it is worthwhile consulting some type of dictionary. However, they may not be able to find a solution there. Schofield (1982: 185) draws an analogy between a mechanic and students attempting to fix their linguistic problems through dictionary.

"We may think of learners as opening the dictionary and being provided with words to fit the context. But it is not so simple. Like a mechanic they have to locate the faulty part first, extract it, and then seek replacement in the store, where it might or might not be in store".

We can extend the analogy further by supposing that in some cases the mechanic might not be able to solve his mechanical problem nor the student his language problem. Two main reasons can explain this. First there might be problems with the machinery used by the mechanic or the dictionary used, or the problem might be with the knowledge of the mechanic or the student. Returning to our topic, we will deal first with the types of problems in look-up caused by the nature of the dictionary used.

To start with, Nesi (2001) using error analysis methods; investigated how the EFL dictionaries -OALD, LDOCE and CULD - were responsible for many problems made by various groups of English language learners. She found that in many ways the dictionaries failed to supply the necessary information concerning registers, collocations and meaning. Nesi (ibid) concluded that one of the reasons for their shortcomings is that publishers continue to compile single works intended to assist students with all four skills areas. Also, dictionaries are still designed for users from all possible cultural and linguistic backgrounds. This criticism is even valid for the preeminent Hornby's OALD, as it is noticed that dictionary, with all its merits it has an essential demerit that it does not take into account the user's linguistic; a thing that made some scholars call for designing dictionaries including "contrastive core grammar" in the text and that an index could appear at the end of the dictionary to explain culturally- specific lexical items in the national language, 
Arabic in our case. Equally, Rundell (1997) in another study of semantic, collocational and stylistic errors in a corpus, blamed the inaccurate or incomplete information in dictionary entries. He reports that lexical items including "reminisce", "debris", "new-fangled", commonly present problems to students while they are encoding. In most cases the dictionary fails to inform users that "reminisce" carries certain syntactic restrictions, such as the fact that it must be followed by the preposition "about", and that "debris" has the meaning of "mass destruction" and "new-fangled" does not have a positive connotation.

Researchers increasingly point out the necessity of ease of access of dictionaries. A dictionary should not only contain correct information but present it in ways that the target user can easily exploit it. This goes under the umbrella term of "user-friendliness" (e.g., guidewords, relief print, the use of limited defining vocabulary, cross-references, access from different look-up starting points, minimum use of grammatical codes, visual display on CD-ROM, pronunciation enhancement on computer, authentic examples arranging senses in order of commonness, etc.). Yet researches in EFL lexicography (e.g. Poulet, 1999, Stein, 2002) indicate that students often have difficulty locating and understanding the increasingly sophisticated EFL dictionary features which necessitate special training. Cowei (2002: 206) warns about this mismatch:

"There is a real danger of opening up a gap which is known to exist between the sophistication of some features of dictionary design and the users' often rudimentary reference skills".

At the same time, instructors have responsibility to teach students to use new features within dictionaries effectively.

Regarding the second main cause of look-up difficulties, namely students' knowledge, we shall account for some of these below. Stein (2002: 31) indicates that research into dictionary use over the last decade has shown that many dictionary users are unable to find and extract from the dictionary the information it holds for them. She suggests the following reasons:

a) Total or partial lack of knowledge of what information the dictionary provides and how it is presented.

b) Underdeveloped dictionary skills.

c) Lack of awareness on the part of the users that the lower their command of the language, the more they have to double-check.

d) Difficulties in identifying appropriate senses.

e) Unfamiliarity with the grammatical system used. This may concern the grammar as such, or only specific distinctions or terminologies.

Alternatively, look-up problems may be caused by wrong habits of learners. Of course, the commonest one is haste in looking up a dictionary, regarding it as a last resort to be used mechanically. Research by Tono (1989:18) equally found that learners have no patience with consulting dictionaries and tend to focus on material appearing at the beginning of the entry. This antipathy towards dictionaries could be so great that students eschew using them where they are needed most. For example, there are the "faux aims" like the French "actions" in the sense of "share" and German "Aktion" which a student might confuse because of interlingual judgment. Also, many EFL students systematically misinterpret dictionary entries (Nesi and Meara, 1994). They (ibid: 14) mention two reasons:

"The dictionary users latch onto a part on the dictionary definition without really understanding how it relates to the word they are looking up. Also, the dictionary may be misleading from the user's point of view.

It is hoped that dictionary writers will improve dictionaries and that teachers will train their students to use their dictionaries effectively.

\section{Methods OF Teaching Dictionary SKILlS}

Teaching dictionary skills is an important yet often neglected activity area in pedagogy. Many instructors and students often view consulting the dictionary as a mechanical, somewhat passive task to be performed after all fails. Dictionary use, however, is a complex, multi-faceted activity which requires some specific preparation. Up to this point, considerable attention has been paid to examining EFL dictionary entries and making various recommendations as to how they can be improved to better serve language learners. Emphasis, however, must also, according to Nesi (1999:71), fall on teaching students how to use the work they already possess. Other researchers stress the same point. Tickoo (1989:60), for example, claims that guidance is necessary for the appropriate use of monolingual dictionaries. He stresses the fact that even the creation of better EFL dictionaries (e.g. electronic or bilingualised) has not reduced the need for individual judgment. More specifically, Walz (1990:34) gives several arguments as to why a dictionary should be taught. He says that first of all:

1- The dictionary is an essential source of information about the language,

2- It can be a tool for lifelong learning since learners will add to their vocabulary throughout their entire lives, and, therefore, it is worth learning the skills, and

3 - It is not a dull, dry reference book and it can be used for more than just practising "safe lex".

Regarding methods of teaching this essential learning tool, the most obvious way is incorporating it in students' and teachers' syllabi. But as critics like Poulet (2002) believe, that up to the 1980s dictionary skills and the teaching of dictionary skills were largely ignored in the programs of instruction and training of future teachers. This can be easily explained by the fact that the majority of teachers considered dictionary use for beginning and intermediate students as hindrance rather than a helpful tool, even if some recognized learners' ability and positive attitude towards using the 
dictionary. Syllabus designers allotted almost no space to lexicography in their ELT courses as we will see from examining the syllabi of the four Sudanese universities under study.

Skills and strategies for using dictionary should be taught in every classroom in the form of explicit teaching, for then students are not learning about dictionaries but about language and such instruction can extend over courses and modules and should continue throughout the students' academic career, rather than being relegated to a class period or two at the beginning of the term. But as Bejoint (1994:210) points out that dictionary consultation skills are complex and not readily acquired through active format, and he compares learning such skills to reading as both activities are learned through continuous practice. A related point concerns establishing valid and reliable standards for assessing dictionary skills component. This can now be done using Tono's (1988) or Nesi's (1999) checklists. Moreover, educators now increasingly allow non-electronic dictionaries, in reading and writing exams, making the test more like a real-life task.

A second method is the use of dictionary monographs. Indeed several useful pamphlets have been published to assist students in using EFL dictionaries. There is Whitcut's (1995) "Working with LDOCE"; Kirkpatrick's (1985): "Chambers Universal Learners' Workbook" and Barridge and Adams (1991): "Using Oxford Leamer's Dictionaries in the Classroom". The advantage of such guides is that exercises are commonly included along with the description of the dictionary. Rather than merely reading what type of information the dictionary offers and how such material is organized, users are given opportunities to work step-by-step with dictionary entries. Guides which are to be of value, writes Lamy (1985:31), should go beyond description and show students how to find needed information not reconstruct how the lexicographers have come to design the dictionary. Also, users must be given specific assistance in employing the dictionary for both decoding and encoding. Moreover, guides alone cannot prepare students to use their dictionaries optimally. Instructors have to become involved. One more particular drawback to some of the guides is that they advertise features of their dictionary (e.g. best seller, hugest language corpus, electronically enhanced, userfriendly-oriented, etc) than they deal with the steps students must follow to locate and use various types of information (Stark,1996). Hence teachers must understand the skills required of dictionary users and be prepared to engage students actively in using the dictionary.

Alternatively, EFL dictionaries may include the instruction material in the introductory section. The 1995 edition of LDOCE, for instance, illustrates dictionary entries in hart form and guidance concerning "how to choose the Right word and use it in the Right way" In CCELD less information concerning dictionary use is provided in the front matter or appendices. The authors have elected to explain certain grammatical codes within the A---Z text. Such a practice, however, may make it more difficult to locate guidance about the dictionary. The CULD, while providing a satisfactory explanatory material for understanding grammatical codes, status and usage labels and definitions, lacks extensive guidance for employing them in the dictionary.

\section{CONCLUSION}

We are here to say that there is an increasing focus on lexicography and the aspects of monolingual dictionaries related to the developments in linguistics including phonology, syntactic theory, the lexical approach, and corpus linguistics. All of these developments have slowly found their way into EFL lexicography that is currently casting away tradition and utilizing the new insights into their entries. So we can assert that lexicographers have carried out their task in professional manner to produce different types of dictionaries. However, Syllabus designers as well as English language teachers have to incorporate these dictionaries in their work, so that dictionaries can be seen as effective and integrative educational tools in language education. The dictionary should be consulted not for looking up the meaning only - as this is the general belief about dictionaries - but it would rather be seen as an authoritative source of language, as it can almost tell the user with every detail about other language aspects in addition to the meaning. Dictionaries shall be seen as the first pedagogical aid which the teacher should keep company in his teaching routine, as well as it should be a good resort for the leaner as an authenticated learning source of linguistic knowledge.

\section{REFERENCES}

[1] Atkins, B. T.S. (ed.). (1998). Using Dictionaries: studies of dictionary use by language learners and translators. Niemeyer: Tübingen.

[2] Baxter, J. (1980). The dictionary and vocabulary behavior: a single word or a handful? TESOL Quarterly XIV. 3.325-336.

[3] Bejoint, H. (1994). Tradition and Innovation in Modern English Dictionaries. Oxford: Oxford University Press.

[4] Bejont, and Moulin, A. (1987). The Place of the Dictionary in an EFLProgramme, in Euralex Seminar. Leeds.

[5] Chan, A. (2004). Pocket Electronic Dictionaries and their Use. Hong Kong: Hong Kong University Press.

[6] Cowie, A.P. and Howarth, P. (1996). Phraseological Competence and Written Proficiency. In G.M. Blue and R. Mitchell (eds.), Language and Education. Oxford: Oxford University Press.

[7] Crystal,D.(1981).The Ideal Dictionary, Lexicographer and User. Cambridge: Cambridge University Press.

[8] Crystal,D.(1991). English as a Global Language. Cambridge: Cambridge University Press.

[9] Crystal,D.(2001). The Cambridge Encyclopedia of the English Language (Sixth ed.). Cambridge: Cambridge University Press.

[10] Garcia, M. (2005). Using Monolingual English Dictionaries for Soluton of Lexical Problems of Mexican Students. Unpublished Ph.D. Thesis. Great Britain: University of Essex.

[11] Graddol, L. (2000). English as a Global Language. London: The British Council. 
[12] Hartmann, R.R.K. (1991). What is the Use of Learners' Dictionaries? Institute of Language in Education Journal. $8.73-83$.

[13] Hartmann, R.R.K. (2002). Thematic Network Project in the Area of Languages. Subproject 9: Dictionaries. Exeter.

[14] Hartmann, R.R.K. 2003). Lexicography with particular reference to English learners' dictionaries. Language Teaching. 25. 15159.

[15] Hartmann, R.R.K. (1994). The Learners Dictionary: Unilingual or Interlingual? In L. Flowerdew and K.K. Tong (ed.,) Entering Text. Hong Kong: The Hong Kong University.

[16] Hartmann, R.R.K. (1998). Dictionaries and their Users. Exeter: University of Exeter.

[17] Hornby, A.S. (1965). Some Problems of Lexicography. English Language Teaching. 3: 104-110.

[18] Hornby, A.S. (2000). Oxford Advanced Learners Dictionary ( $7^{\text {th }}$ ed.). Oxford: Oxford University Press.

[19] Hulbert, J. (1978). Dictionaries: British and American. London: Deutsch.

[20] Jackson, H. (1988). Words and their Meanings. London: Longman.

[21] Koya,T.(2005). The Acquisition of Basic Collocations by Japanese Learners of English. Ph.D thesis, Waseda University.

[22] Landau, S.I. (1989). Dictionaries: The Art and Craft of Lexicography. New York: C. Scribner and Sons.

[23] Lewis, M. (1999). The Lexical Approach. Rove: Language Teaching Publications.

[24] Nation, I.S.P. (1990). Teaching and Learning Vocabulary. Rowley, M.A. Newbury House.

[25] Nation, I.S.P. (2001). Learning Vocabulary in Another Language. Cambridge: Cambridge University Press.

[26] Nation, P. (2003). The Role of the First Language in Foreign Language Learnin. Asian EEL Journal. vol. 5. issue 2. article 1.

[27] Nesi, H. (2000). The Specification of Dictionary Reference Skills in Higher Education. In R. Hartmann (ed.,) Dictionaries in Language Learning: Recommendations, National Reports and Thematic Reports, TNP subproject 9: Dictionaries. Berlin.

[28] Nesselhauf, N. (2003). The Use of Collocations by advanced learners of English and some implications for teaching. Applied Linguistics. 24(2): 223-242.

[29] Poulet, G. (1999). "Instruction in Dictionary Use and Foreign Language Teacher Training: The English Scene". In R. Hartmann (ed.). European Language Council. Thematic Network Project in the Area of languages sub-projects 9: Dictionaries. 78-82.

[30] Reif, J. (1987). The Development of a Dictionary Concept: an English Learner's Dictionary and an Exotic Alphabet. In The Dictionary and the Language Learner: Papers from the EURALEX Seminar at the University of Leeds, Anthony Cowie (ed.), Max Niemeyer Verlag, Tubingen, p146-158.

[31] Rundell, M. (1999). "Recent Trends in Publishing Monolingual learners' Dictionaries", in R. Hartmann (ed.,) European Language Council. Thematic Network Project in the Area of languages. Subproject 9 Dictionaries 83-098.

[32] Scholfield, P. (1982). "Using the Dictionary for Comprehension" TESOL Quarterly 16.2: 185-194.

[33] Scholfield. (1996). "Dictionary Use in Reception". International Journal of Lexicography 12. 1: 13-34.

[34] Scholfield. (1998). Vocabulary Reference Works in Foreign Language Learning". In N. Schmitt and M. McCarthy (eds,), Vocabulary: Description, Acquisition and Pedagogy, 279-302. Cambridge: Cambridge University Press.

[35] Scholfield. (2002). Why Shouldn't Monolingual Dictionaries be as Easy to Use as Bilingual Ones? [Retrieved January 17,2010, from http/www logman.coml dictionaries/teacher/articles/p-rcholfield- 02. htndj.

[36] Sharpe, P. (1995). Electronic Dictionaries with Particular Reference to the Design of an Electronic Bilingual Dictionary for English-Speaking Learners of Japanese. International Journal of Lexicography 8(1). P. 39-54.

[37] Sinclair, J. (ed.,). (1987). Looking-Up. An Account of the COBUILD Project in Lexical Computing and the Development of Collins Co- Build English Language Dictionary. London: Harper Collins.

[38] Stark, M. (1990). "Dictionary Workbooks. A Critical Evaluation of Dictionary Workbooks for the Foreign Language Learner". Exeter Linguistic Studies 16.

[39] Stein, G. (1990). From the Bilingual to the Monolingual Dictionary. Hamburg University.

[40] Stein, G. (1995). Illustration in Dictionaries. International Journal of Lexicography 4.2: 99-127.

[41] Stein, G. (2002). Better Words: Evaluation of EFL Dictionaries. Exeter: Exeter University Press.

[42] Tickoo, M.L. (ed.,). (1989). Learner's Dictionaries: State of the Art. Singapore: SEAMEO Regional Language Centre.

[43] Tono, Y. (1998). Assessment of the EFL Learner's Dictionary Using Skills. JACET Bulletin 19: 103-26.

[44] Underhill, A. (1989). Using Your Dictionary. Oxford: Oxford University Press.

[45] Walz, J. (1990). The dictionary as a secondary source in language learning. The French Review 64. 1. $79-94$.

[46] West, M. (1953). A General Service List of English words. London: Longman.

[47] West, M. and Endicott, J.G. (1961). The New Method English Dictionary. London: Longman.

[48] Whitcut, J. (1995). The Training of Dictionary Users. Manchester ELT Monograph.

[49] Wright, J. (2001). Dictionaries, Resource Books for Teachers, Oxford University Press, Oxford.

[50] Yorkey, R.C. (1992). Study Skills for Students of English. New York: Mc-Grow Hill Publication.

[51] Zahner, G. (2004). Lexical resources in CALL. Computer Education 23. 172.75.

[52] Zgusta, L. (1971). Manual of Lexicography. The Hague: Mouton.

Al-Nauman Al-Amin Ali El-Sayed is assistant Professor in the English Department-College of Science \& Humanities in Dawadami-Shaqra University - KSA. He got his B.A with (HONOURS - First Class) from Khartoum University as well as an M.A \& Ph.D in applied linguistics. His thesis was entitled" Manifest Intersexuality in Academic Discourse: A Corpus-based Interdisciplinary Study of Geology, Geography and Applied Linguistics Ph.D. Theses) It is the only reference in this field in the Sudan. Dr. El-Ssayed will publish articles accepted in referred journals in Canada, Australia and Finland. 


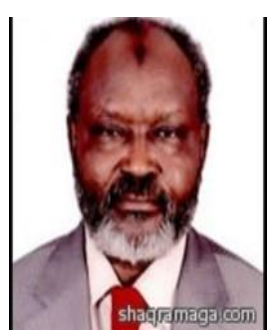

Ahmed Gumaa Siddiek, got his B.A in English with (MERIT) from Khartoum University in (1982). He has an MA in Translation from the Islamic Institute for Translation in Khartoum as well as an M.Ed in (TEFL) from Juba University - Sudan (2002). Mr Siddiek got his Ph.D with (EXCELLENT) in (Language Testing)) in (2004) from Omdurman Islamic University - Sudan. Since then Dr. Siddiek has been lecturing in Sudan and Saudi Arabia. He has published articles in ELT journals in USA, UK, Canada, Finland and Australia. He attended conferences and read papers in Harvard, Purdue, Ohio State University in USA, Germany, France \& Canada. Dr. Siddiek is the Author of: (Assessment of the Sudan School Certificate English Examinations) \& (Language Challenges in Post War Sudan). Both books are available at amazon.net. Dr.Siddiek is a member of editorial Boards of (International Journal of English Linguistic, English Language and Literature Studiesin Canada, and he is an Associate Editor in (International Journal of Applied Linguistics \& English Literat ure - Australia). His major fields of interest are testing, translation, language planning \& English Language Teacher Training. Dr. Siddiek is a member of the Centre for Promoting Ideas (CPI)-USA and the Sudan Studies Association in the USA. 